\title{
$\gamma 3$ GENE DUPLICATION IN A PAIR OF TWINS: UNEQUAL CROSSOVER OR CHIMERISM?
}

\author{
Hideo Matsumoto, ${ }^{1}$ Tokiko MiYazaki, ${ }^{1}$ Yoshinobu NaKao, ${ }^{2}$ \\ Kimiyoshi Tsum, ${ }^{3}$ Hiroko FuJta,${ }^{4}$ Mikio OHTA, ${ }^{5}$ \\ Noboru ODA, ${ }^{5}$ and Kazuhiko ABE ${ }^{6}$ \\ ${ }^{1}$ Department of Legal Medicine, Osaka Medical School, Takatsuki, Osaka 569, Japan \\ ${ }^{2}$ Third Division, Department of Medicine, Kobe University School of Medicine, \\ Kobe 650, Japan \\ ${ }^{3}$ Department of Transplantation Immunology, Tokai University School of Medine, \\ Isehara 259, Japan \\ ${ }^{4}$ Department of Child Health, Faculty of Science of Living, Osaka City University, \\ Osaka 558, Japan \\ ${ }^{5}$ Department of Psychiatry, Osaka City University School of Medicine, \\ Osaka 545, Japan \\ ${ }^{6}$ Department of Psychiatry, School of Medicine, University of Occupational \\ and Environmental Health, Kitakyushu 807, Japan
}

Summary A Japanese family with the dizygotic twins, one of whom has three Gm haplotypes containing at least three $\gamma^{3}$ alleles, was encountered by a zygosity test. Neither of the twins has ever had a blood transfusion. The 28 genetic marker systems have been investigated for the twins including the family members. Neither the genetic marker systems on red and white blood cells, nor polymorphic autosomal markers detected by G-, C-, and Q-banding techniques demonstrated positively the existence of the chimerism in a pair of twins. The mechanism which resulted in the $\gamma 3$ duplication is postulated as being either unequal intercistronic or intragenic crossover. This seems to be the first such case to be found.

\section{INTRODUCTION}

Erythrocytic chimerism in dizygotic twins is common in cattle but appears to be extremely rare in humans. The term 'chimera' has been used in botany to denote an individual plant consisting of tissues of diverse genetic constitution, such as a graft hybrid. In 1945 Owen discovered that the red cells of dizygotic twin cattle were antigenically a mixture of two kinds and that communication between the circulations of binovular bovine twins due to the anastmoses can occur, resulting in an interchange of erythroblasts with persistence throughout life of mixed blood groups. Several human examples of mixed blood in a pair of twins have

Received June 5, 1981 
been reported thus far (Dunsford et al., 1953; Booth et al., 1957; Nicholas et al., 1957). A further case of blood chimerism in male twin concerning red and white cells was reported by Pausch et al. (1979).

It is generally accepted that all immunoglobulin heavy and light polypeptide chains consisting domains have evolved by successive duplication of a common primordial gene which coded for a single domain. It is also known that the limited number of loci for the constant region subclasses (heavy chain) or subtypes (light chain) of human immunoglobulin genes are divided into three main groups. The genes coding for the heavy chains all lie very close to each other. Each distinct immunoglobulin gene exists in a variety of allelic forms which respectively give rise to immunoglobulin chains with characteristic amino acid markers (allotypes). Extensive analysis of the inheritance of allotypic markers indicates that $\mathrm{Gm}$ markers are found in three of the four $\gamma \mathrm{H}$ subclasses and that the combination of $\mathrm{Gm}$ markers on the chromosome is not random, but these markers are always present in certain fixed combinations, referred to as haplotypes, which are inherited together.

The analysis of the inheritance of allotypic markers also indicates that gene coding for the $\lambda$ light chain is not at all linked to the gene coding for the $\kappa$ chain or to the genes coding for the heavy chains, though three $\gamma$-cistrons and $\alpha 2$-cistrons are closely linked. Genetic analysis of appropriate families strongly support the presence of a single locus for each of the $\kappa, \gamma 1, \gamma^{2}, \gamma^{3}$ and $\alpha 2$ genes. The sequence is assumed to be $\mu,(\alpha 1, \alpha 2), \gamma^{4}, \gamma^{2}, \gamma^{3}$, and $\gamma l$ for heavy chains (Lefrance et al., 1977). Gm gene complex deviating from the common ones possibly arises by mutation or crossing over (Steinberg et al., 1968; van Loghem and Natvig, 1970; van Loghem et al., 1980). Lefrance et al. (1976) reported three uncommon Gm haplotypes which have been transmitted through 3 generations of two related Lebanese and Syrian families and explained the observed data by either a partial or a total structural deletion of the constant portion of the IgG3 heavy chain.

This paper is concerned with a Japanese family with dizygotic twins, one of whom has three Gm haplotypes, that is, at least three $\gamma^{3}$ alleles. The family was at first investigated for zygosity of the twins. Neither of the twins has ever had a blood transfusion. This seems to be the first such case to be found.

\section{MATERIALS AND METHODS}

The propositus twins are healthy elementary school boys aged 7, who were tested for zygosity with their family for the first time in April 1978. The 22 determined genetic marker systems except for the Tf, Gc, Pi and PGM systems were defined using standard techniques. Isoelectric focusing with use of Ampholine LKB were performed for Tf, Gc, Pi and PGM subtyping according to the methods previously described (Matsumoto et al., 1980; Matsumoto et al., 1981). The classical hemagglutination inhibition test on microfiocculation slides was used for immunoglobulin allotype determinants according to the methods previously described 
Table 1. Reagents used for Gm, Am, and Km allotyping.

\begin{tabular}{|c|c|c|c|c|}
\hline Chain & Domain & Allotype & Antiserum & Coating \\
\hline \multirow[t]{4}{*}{$\gamma 1$} & $\mathrm{CH} 1$ & $\operatorname{Glm}(z)$ or 17 & Human 3272 & Anti-D 3417 \\
\hline & $\mathrm{CH} 1$ & $(f)$ or 3 & Human 2871 & Anti-D 3097 \\
\hline & $\mathrm{CH} 3$ & (a) or 1 & Human 3294 & Anti-D 3417 \\
\hline & $\mathrm{CH} 3$ & $(x)$ or 2 & Human 2984 & Anti-D 2880 \\
\hline$\gamma^{2}$ & $\mathrm{CH} 2$ & $\mathrm{G} 2 \mathrm{~m}(n)$ or 23 & Rabbit 9547 & Protein Jasp \\
\hline \multirow[t]{8}{*}{$r 3$} & $\mathrm{CH} 2$ & $\mathrm{G} 3 \mathrm{~m}(g)$ or 21 & Rabbit 5306 & Anti-D 3359 \\
\hline & $\mathrm{CH} 2$ & $\left(b^{1}\right)$ or 5 & Human 2933 & Anti-D 2127 \\
\hline & $\mathrm{CH} 2$ & $\left(b^{4}\right)$ or 14 & Human 1075 & Anti-D 3656 \\
\hline & $\mathrm{CH} 2$ & $(s)$ or 15 & Human 2624 & Anti-D 3068 \\
\hline & $\mathrm{CH} 2$ & $(t)$ or 16 & Human 2639 & Anti-D 3068 \\
\hline & $\mathrm{CH} 3$ & $\left(b^{0}\right)$ or 11 & Human 2357 & Anti-D 2127 \\
\hline & $\mathrm{CH} 3$ & $\left(b^{3}\right)$ or 13 & Human 2277 & Anti-D 2127 \\
\hline & CH 3 & $\left(b^{5}\right)$ or 10 & Human 2123 & Anti-D 2127 \\
\hline \multirow[t]{2}{*}{$\alpha 2$} & $\mathrm{CH} 2$ & $\mathrm{~A} 2 \mathrm{~m}(l)$ & Human Jel & Protein Mens \\
\hline & CH 2 & (2) & Human Tay & Protein Ford \\
\hline \multirow[t]{2}{*}{$\kappa$} & $\mathrm{CL}$ & $\mathrm{Km}(1)$ & Human 2125 & Anti-D 2290 \\
\hline & $\mathrm{CL}$ & (3) & Human Neely & Anti-D Ham \\
\hline
\end{tabular}

(Matsumoto and Takatsuki, 1968). These serum samples were also tested for Glm $\left(a, x, f\right.$, and $z$ ), $\mathrm{G} 2 \mathrm{~m}(n)$, and $\mathrm{G} 3 \mathrm{~m}\left(b^{0}, b^{1}, b^{3}, b^{4}, b^{5}, s, t, g\right)$, and $\mathrm{Km}(1, b)$ systems including $\operatorname{A} 2 \mathrm{~m}(1,2)$ in Dr. E. van Loghem's laboratory in the Netherlands. The $\mathrm{Gm}$ systems and reagents used in the study are shown in Table 1. The standard microcytotoxity test was used to determine the HLA system in this study. The following HLA specificities were identified: A1, A2, A3, A9, A10, A11, AW24, $\mathrm{A} 25, \mathrm{A26}, \mathrm{A} 29, \mathrm{AW} 30$, and $\mathrm{AW} 31$ at the A locus, B5, B7, B8, B12, B13, B14, B15, $\mathrm{B} 17, \mathrm{BW} 22, \mathrm{~B} 27, \mathrm{BW} 35, \mathrm{~B} 37, \mathrm{BW} 51, \mathrm{BW} 52$, and BW54 at the B locus, and CW3 and CW4 at the $\mathrm{C}$ locus. Chromosome preparations for G-, C-, and Q-banding were made from peripheral blood leucocytes using a 3-day culture with various media. After staining, some of the mitoses were photographed and karyotyped. All the investigation on the twins was done on three different bleedings over a period of two years.

\section{RESULTS AND DISCUSSION}

The results of the genetic marker systems on red and white blood cells and erythrocyte enzymes of the family Mit are shown in the pedigree (Fig. 1). No exception to the Mendelian inheritance could be observed except for the Gm system as seen in Table 2. As shown in Fig. 1, the twins are dizygotic because of the differ- 


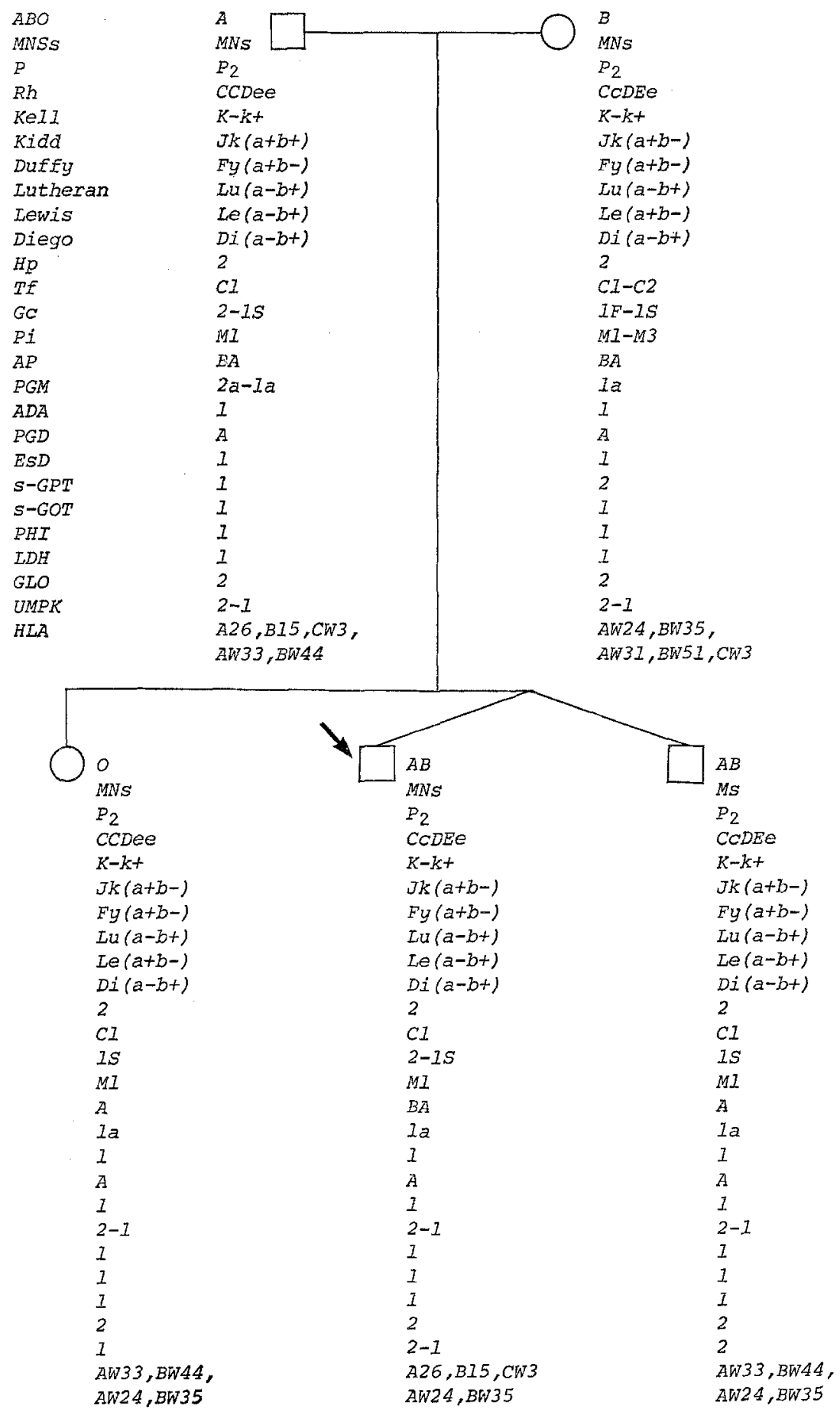

Fig. 1. The blood groups of the family Mit. 
Table 2. Gm, Am, and $\mathrm{Km}$ phenotypes and haplotypes of the family Mit.

\begin{tabular}{|c|c|c|c|c|c|c|}
\hline & \multicolumn{3}{|r|}{$\mathrm{Gm}$} & \multirow{2}{*}{$\frac{\mathrm{Am}}{\alpha 2}$} & $\mathrm{Km}$ & \\
\hline & $r^{1}$ & $\gamma^{2}$ & $r^{3}$ & & & \\
\hline & $\begin{array}{llll}z & a & x & f\end{array}$ & $n$ & $\begin{array}{cccccccc}g & b^{0} & b^{1} & b^{4} & b^{3} & b^{5} & s & t\end{array}$ & 12 & 13 & \\
\hline I-1 (fa.) & +++- & - & ++--+++ & +- & -+ & \\
\hline I-2 (mo.) & ++-+ & + & -+++++++ & -+ & ++ & \\
\hline $\mathrm{II}-1$ & +++- & - & ++--++++ & $+t$ & -+ & \\
\hline $\mathrm{II}-2$ & ++++ & + & ++++++++ & ++ & -+ & \\
\hline $\mathrm{II}-3$ & ++++ & + & ++++++-- & ++ & -+ & \\
\hline I-1 (fa.) & $\mathrm{Gma}, \mathrm{x}, z ; \ldots ; g /$ & Gma &,$z ; \ldots ; b^{0}, b^{3}, b^{5}, s, t$ & & & $; \mathrm{A} 2 \mathrm{~m}(l)$ \\
\hline I-2 (mo.) & $\mathrm{Gma}, \mathrm{f} ; \mathrm{n} ; \mathrm{b}^{0}, \mathrm{~b}^{1}$ & $1, b^{4}, b$ & $3^{3}, b^{5} / G m a, z ; . . ; b^{0}, b^{3}, b^{5}, s, t$ & & & ; $\mathrm{A} 2 \mathrm{~m}(2) \quad \mathrm{Km}(1,3)$ \\
\hline II-1 & $\mathrm{Gma}, \mathrm{x}, z ; \ldots ; \mathrm{g} /$ & Gma &,$z ; \ldots: b^{0}, b^{3}, b^{5}, s, t$ & & & ; $\mathrm{A} 2 \mathrm{~m}(1,2) \mathrm{Km}(3)$ \\
\hline $\mathrm{II}-2$ & $\mathrm{Gma}, \mathrm{x}, z ; \ldots ; \mathrm{g} /$ & Gma & $\mathrm{f} ; \mathrm{n} ; \mathrm{b}^{0}, \mathrm{~b}^{1}, \mathrm{~b}^{4}, \mathrm{~b}^{3}, \mathrm{~b}^{5} / \mathrm{Gma}, \mathrm{z} ;$ & $; b^{0}, b^{3}, b$ & ${ }^{5}, \mathrm{~s}, \mathrm{t}$ & ; $\mathrm{A} 2 \mathrm{~m}(1,2) \mathrm{Km}(3)$ \\
\hline II-3 & $\mathrm{Gma}, \mathrm{x}, z ; \ldots ; \mathrm{g} /$ & Gma &, $\mathrm{f} ; \mathrm{n} ; \mathrm{b}^{0}, \mathrm{~b}^{1}, \mathrm{~b}^{4}, \mathrm{~b}^{3}, \mathrm{~b}^{5}$ & & & ; $\mathrm{A} 2 \mathrm{~m}(1,2) \mathrm{Km}(3)$ \\
\hline
\end{tabular}

ences in five systems: MNSs, Gc, AP, UMPK and HLA. These figures have not changed over a period of two years.

The 10 genetic marker systems on red blood cells investigated in this study did not reveal the existence of the erythrocytic chimerism in the twins. HLA typing was performed to detect a possible chimerism of the white blood cells. Both twins are not HLA identical, but no evidence of the chimerism could be found. Furthermore, polymorphic autosomal markers detected by Q-, G-, and C-banding techniques did not demonstrate the existence of two different lymphocyte populations in both brothers either. In regard to the $\mathrm{C}$-banding method, marked difference was found in the intensity of fluorescence on the centromeric region chromosome 16. However, this seems to be due to individual variation, because the same karyotype was obtained from all the cells and it was confirmed that the chromosome was derived from the paternal chromosome (Fig. 2). Thus, a lymphocyte chimerism was not demonstrated since it was not confirmed that the twins possess cells derived from more than one zygote lineage using polymorphisms of autosomes.

Concerning the Gm system, child 2 has three Gm haplotypes, in other words at least three $\gamma 3$ alleles. In child 3 not even a trace of $\mathrm{Gm}(\mathrm{s})$ and/or $\mathrm{Gm}(\mathrm{t})$ could be demonstrated (Table 2). Thus, either an unequal crossover may be considered or a chimerism, which is one way only (a take in child 2 and no take in child 3 ). Genetically determined Gm allotypes are carried by the heavy chains of IgG1, IgG2, and IgG3. The genes coding for them are transmitted as units referred to as haplotypes. Thus, the $\mathrm{Gm}$ allotypes are always present in fixed combinations characteristic of ethnic groups. The Gm haplotypes usually found in Mongoloid

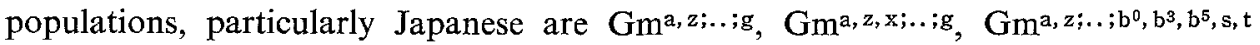

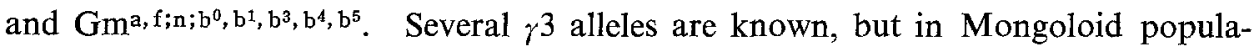



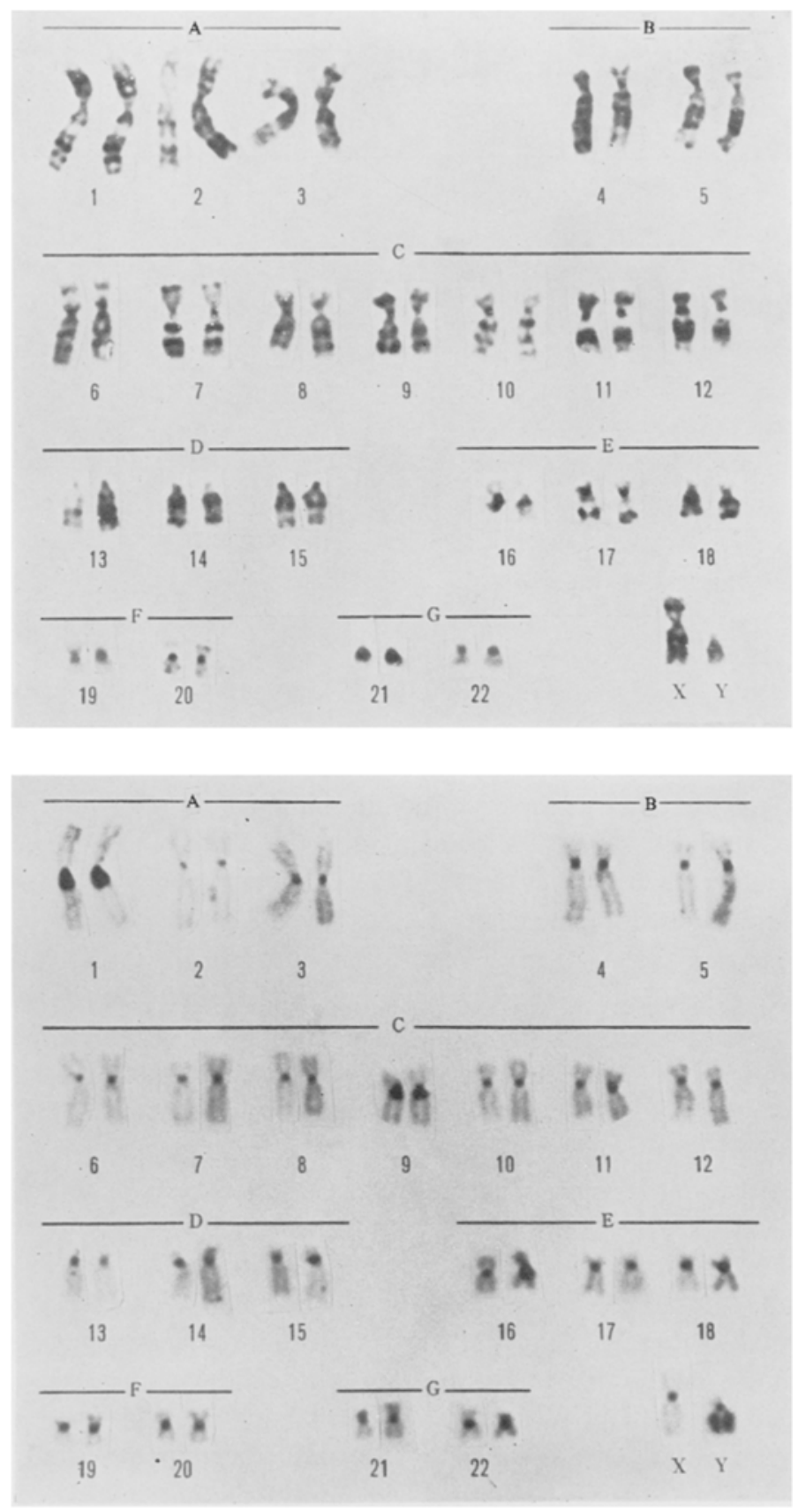

Fig. 2. G-banded (upper) and C-banded (lower) karyotypes of proband. 
tions three different $\gamma^{3}$ alleles, $\mathrm{G} 3 \mathrm{~m}(g), \mathrm{G} 3 \mathrm{~m}\left(b^{0}, b^{3}, b^{5}, s, t\right)$, and $\mathrm{G} 3 \mathrm{~m}(b)$, occur. The last allele, G3m (b) carries all $\mathrm{G} 3 \mathrm{~m}\left(b^{0}\right),\left(b^{1}\right),\left(b^{3}\right),\left(b^{4}\right)$ and $\left(b^{5}\right)$ allotypes, while the second one is lacking $\mathrm{G} 3 \mathrm{~m}\left(b^{1}\right)$ and $\left(b^{4}\right)$. G3m $(g)$ carries $(g)$ on $\mathrm{CH} 2$ domain. $\mathrm{G} 3 \mathrm{~m}(b)$ carries $\left(b^{1}\right)$ and $\left(b^{4}\right)$ on $\mathrm{CH} 2$ domain and $\left(b^{0}\right),\left(b^{3}\right)$, and $\left(b^{5}\right)$ on $\mathrm{CH} 3$ domain. $\mathrm{G} 3 \mathrm{~m}(s, t)$ are on $\mathrm{CH} 2$ domain.

In the family Mit there are the following $\gamma 1-\gamma 3$ alleles: (1) $z, a, x ; g$ (2) $z, a$; $b^{0}, b^{3}, b^{5}, s, t$ and (3) $f, a, b^{0}, b^{1}, b^{3}, b^{4}, b^{5}$. The parents in the family each have only two $\gamma 1-\gamma 3$ alleles: the father, (1) and (2); the mother, (2) and (3). The child 3 has inherited the $\gamma 1-\gamma 3$ allele (1) from his father and the allele (3) from his mother. The child 2 has inherited the $\gamma 1-\gamma 3$ allele (1) from his father, the allele (3) from his mother, and the allele (2) either from his father or mother. Simultaneous presence of all the three alleles can only be explained by admitting chimerism or duplication by crossing-over. Supposing it is due to a chimerism between child 2 and child 3 , there are three possibilities as to what is the original genotype of child 2 : (1) $z$, $a$; $b^{0}, b^{3}, b^{5}, s, t / z, a ; b^{0}, b^{3}, b^{5}, s, t$ (2) $z, a ; b^{0}, b^{3}, b^{5}, s, t / f, a ; b^{0}, b^{1}, b^{3}, b^{4}, b^{5}$ and (3) $z, a, x ; g / z, a ; b^{0}, b^{3}$, $b^{5}, s, t$. As one of the explanation for the duplicated $\gamma^{3}$ allele in child 2, introduction from child 3 can be postulated, though positive evidence of chimerism has not been obtained. Typing for $\mathrm{A} 2 \mathrm{~m}$ allotypes gave no further information. Father was $A 2 m(1-2+)$ and mother $A 2 m(1+2-)$. All three children were $A 2 m(1+2+)$.

Alternatively, the duplication of $\gamma^{3}$ genes observed to have happened in one of a twin pair may be explained by the postulation of unequal intercistronic crossover (Fig. 3) or unequal intragenic crossover (Fig. 4). Natvig et al. (1971) described the gene complex involving two pairs of $\gamma \mathrm{G} 1$ genetic markers which ordinarily behave as homoalleles $G m^{2}$ and $G m^{\mathrm{f}}$ for the Fd part of $\gamma \mathrm{Gl}$ molecules, and $G m^{\mathrm{a}}$

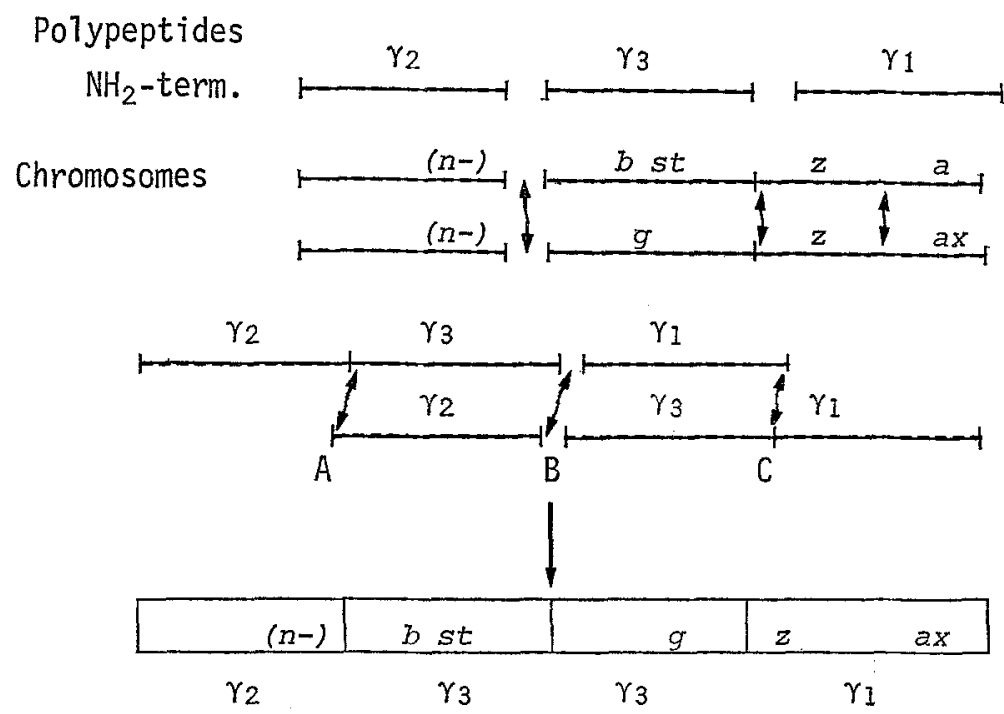

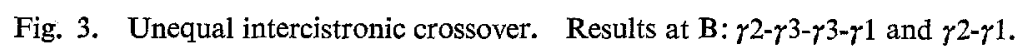




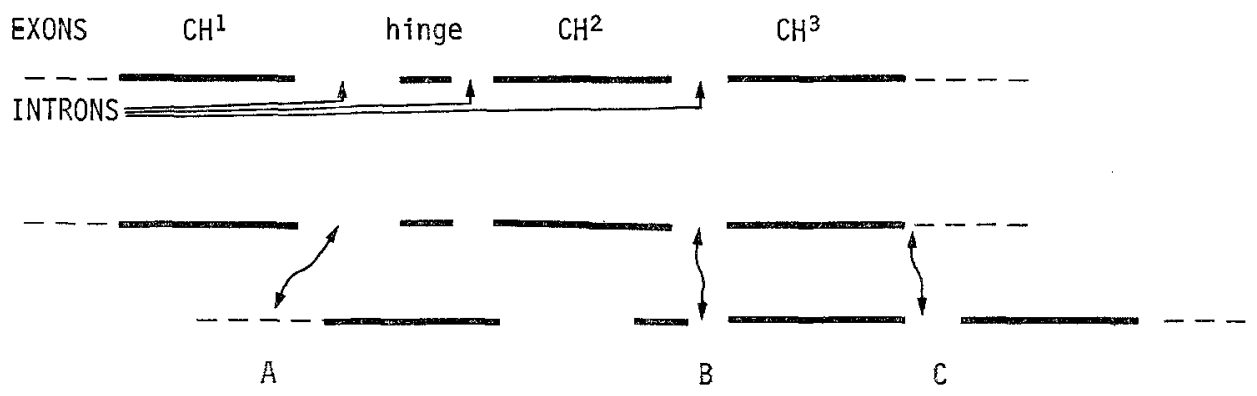

Fig. 4. Unequal intragenic crossover. Results at $\mathrm{B}$ : $\mathrm{CH} 1$-hinge- $\mathrm{CH} 2-\mathrm{CH} 2-\mathrm{CH} 3$ and $\mathrm{CH} 1$-hingeCH3,

and non- $a$ for the Fc part and explained that the appearance of such homoalleles on the same chromosome probably resulted from a recent gene duplication, giving rise to two $\gamma \mathrm{G} 1$ cistron on one chromosome. Unequal intercistronic crossover will result in duplication and deletion of a whole cistron. In Fig. $3, \gamma^{2}$ at $\mathrm{A}, \gamma^{3}$ at B, and $\gamma 1$ at $\mathrm{C}$, will be involved. Unequal intragenic crossover will similarly results in new genes with partial duplication and deletion of $\mathrm{CH} 1, \mathrm{CH} 2$, and $\mathrm{CH} 3$ (at $\mathrm{A}$, B, and C, Fig. 4). The uncommon haplotypes found in the family with an excess of $\mathrm{G} 3 \mathrm{~m}$ allotypes may be explained by either mechanism. The quantitative IgG subclass determination in the sera of members heterozygous for a duplicated gene do not show increased levels of the gene involved. Apparently, the subclass level is not determined by the number of structural genes but by regulatory genes.

\section{REFERENCES}

Booth, P.B., Plaut, G., James, J.D., Ikin, E.W., Moores, P., Sanger, R., and Race, R.R. 1957. Blood chimera in a pair of twins. Brit. med. J. i : 1456-1458.

Dunsford, I., Bowley, C.C., Hutchison, A.M., Thompson, J.S., Sanger, R., and Race, R.R. 1953. A human blood-group chimera. Brit. med. $J$. ii: 81 .

Leirance, G., Rivat, L., Rivat, C., Loiselet, J., and Ropartz, C. 1976. Evidence for 'deleted' and 'silent' genes homozygous at the locus coding for the constant region of the $r 3$ chain. Am.J. Hum. Genet. 28 : 51-61.

Lefrance, G., Rivat, L., Salier, J.P., Loghem, E. van., Aydenian, H., Zalzal, P., Chakhachiro, L., Loiselet, J., and Ropartz, C. 1977. Recombination, mutation, or constitutive expression at a Gm locus and familial hypergammaglobulinemia. Am. J. Hum. Genet. 29: 523-536.

Loghem, E. van., and Natvig, J.B. 1970. Uncommon Gm gene complexes. Vox Sang. 18: 421-434. Loghem, E. van, Sukernik, R.I., Osipova, L.P., Zegers, B.J.M., Matsumoto, H., Lange, de G., and Lefrance, G. 1980. Gene deletion and gene duplication within the cluster of human heavy chain genes. J. Immunogenet. 7: 285-299.

Matsumoto, H., and Takatsuki, K. 1968. Gm factors in Japan: population and family studies. Jpn. J. Hum. Genet. 13: 10-19.

Matsumoto, H., Matsui, K., Ishida, N., Ohkura, K., and Teng, Y.S. 1980. The distribution of Gc subtypes among the Mongoloid populations. Am. J. Phys. Anthrop. 53: 505-508. 
Matsumoto, H., Matsui, K., Tamaki, Y., Shibata, K., Kawai, Y., Hara, T., and Suzuki, K. 1981. Distribution of Tf, Pi, and PGM subtypes in Japanese and their application in paternity case. Am. J. Forensic Med. Pathol. (in press).

Natvig, J.B., Michaelsen, T.E., and Kunkel, H.G. 1971. Evidence for recent duplicationsamong certain gamma globulin heavy chain genes. J. Exp. Med. 133: 1004-1014.

Nicholas, J.W., Jenkins, W.J., and Marsh, W.L. 1957. Human blood chimeras: a study of surviing twins. Brit. med. $J$. i: 1458-1460.

Owen, R.D. 1945. Immunogenetic consequences of vascular anastomoses between bovine twins. Science 102: 400-401.

Pausch, V., Bleier, I., Dub, E., Kirnbauer, M., Weirather, M., Würger, G., and Mayr, W.R. 1979. A further case of chimeric twins: genetic markers of the blood. Vox Sang. 36: 85-92.

Steinberg, A.G., Muir, W.A., and McIntire, S.A. 1968. Two unusual Gm alleles: their implications for the genetics of the Gm antigens. Am. J. Hum. Genet. 20: 258-278. 